\title{
Histidine-based lipopeptides enhance cleavage of nucleic acids: interactions with DNA and hydrolytic properties
}

\author{
Marie Bélières, Christophe Déjugnat, Nadia Chouini-Lalanne* \\ Laboratoire des Interactions Moléculaires et Réactivité Chimique et Photochimique (IMRCP), \\ UMR 5623 (CNRS/Université Paul Sabatier), Toulouse, France \\ *corresponding author: lalanne@,chimie.ups-tlse.fr
}

\section{SUPPORTING INFORMATION}

Fluorescence titration curves of DNA-EB complexes with lipopeptides

page 2

Figure S1. Fluorimetric titration of EB-DNA complexes with N1

page 2

Figure S2. Fluorimetric titration of EB-DNA complexes with N10

page 3

Figure S3. Fluorimetric titration of EB-DNA complexes with $\mathbf{N 1 2}$

page 3

Figure S4. Fluorimetric titration of EB-DNA complexes with C10

page 4

Figure S5. Fluorimetric titration of EB-DNA complexes with N10G

page 4

Figure S6. Fluorimetric titration of EB-DNA complexes with C10N10

page 5 


\section{Fluorescence titration curves of DNA-EB complexes with lipopeptides}

$C C^{D N A}$ values were estimated from the plots of the $I_{n} / I_{0} E B$ fluorescence ratios as a function of the concentrations of lipopeptides. The profiles showed a sharp decrease when the ethidium bromide was displaced. The curves were adjusted with the following SigmoidBoltzmann equation:

$$
y=\frac{A_{1}-A_{2}}{1+e^{\left[\frac{x-x 0}{d x}\right]}}+A_{2}
$$

where $y$ is the $I_{n} / I_{0}$ ratio, $x$ is related to the lipopeptide concentration $(x=\log c)$, and $A_{1}$ and $A_{2}$ are the upper and lower limits of the sigmoid.

According to Aguiar et al. [J. Aguiar, P. Carpena, J. A. Molina-Bolivar, C. Carnero Ruiz, J. Coll. Int. Sci. 2003, 258, 116-122], the CC ${ }^{\mathrm{DNA}}$ corresponded to the $x_{0}$ values.

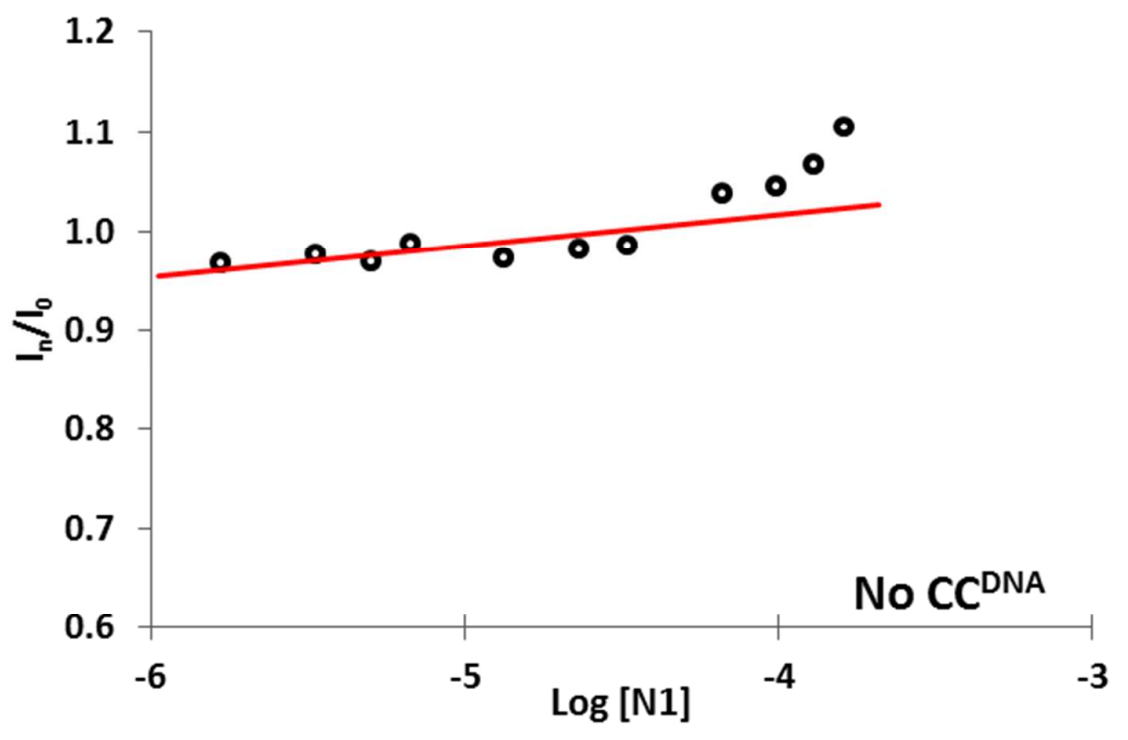

Figure S6. Fluorimetric titration of EB-DNA complexes with N1 


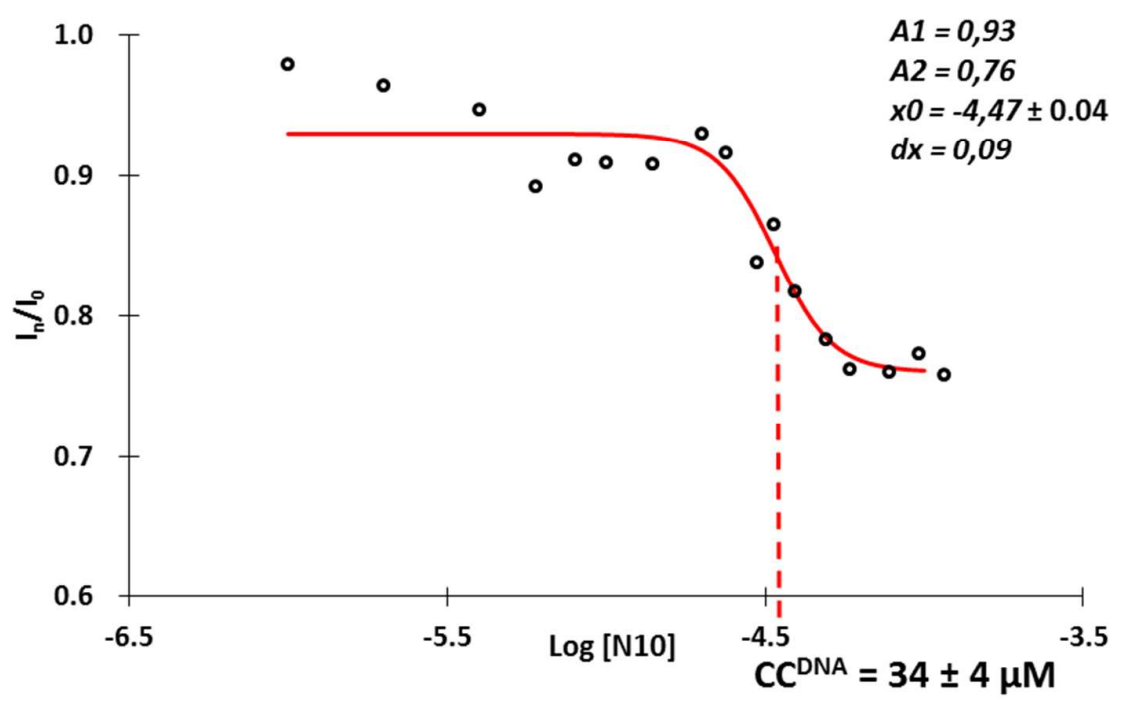

Figure S7. Fluorimetric titration of EB-DNA complexes with N10

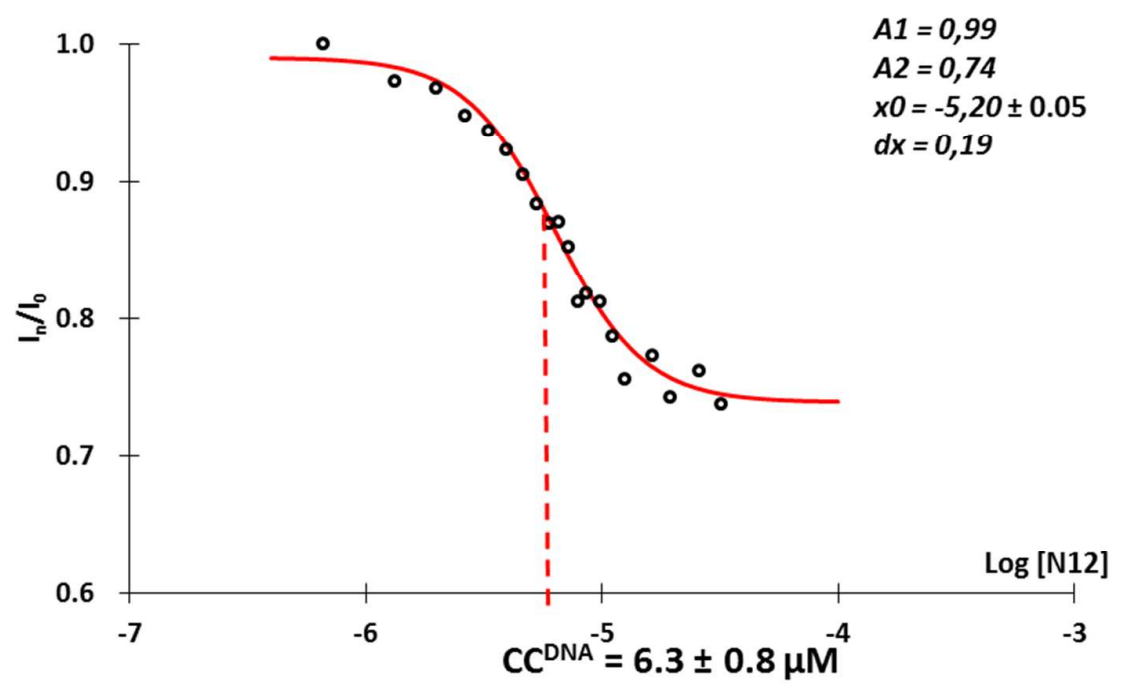

Figure S8. Fluorimetric titration of EB-DNA complexes with N12 


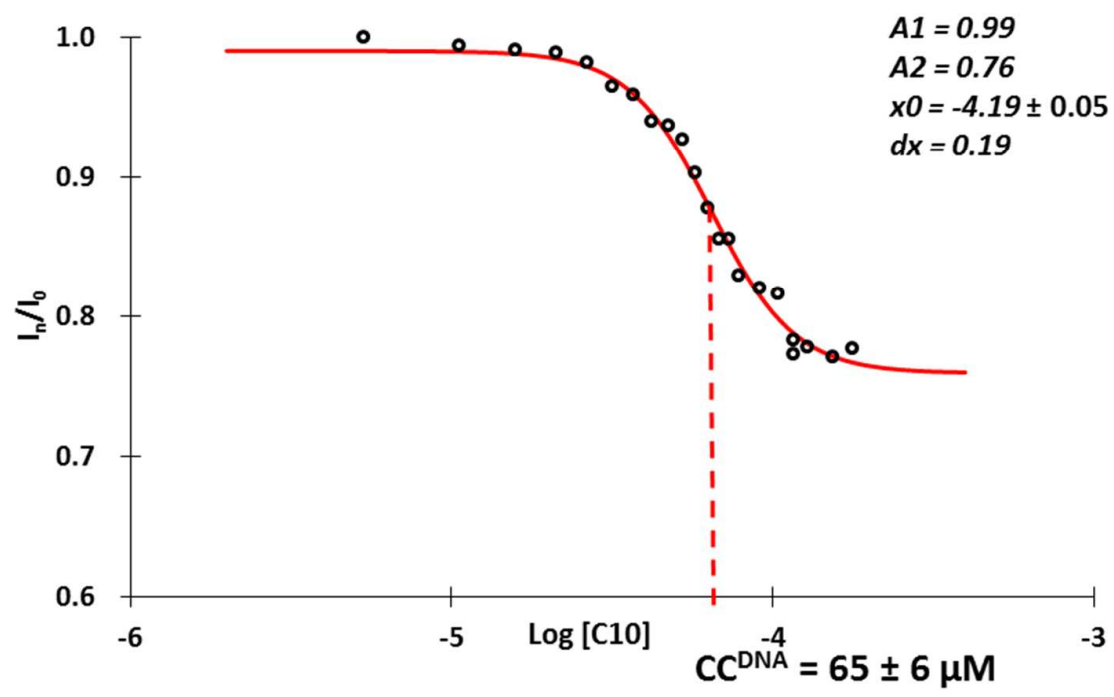

Figure S9. Fluorimetric titration of EB-DNA complexes with C10

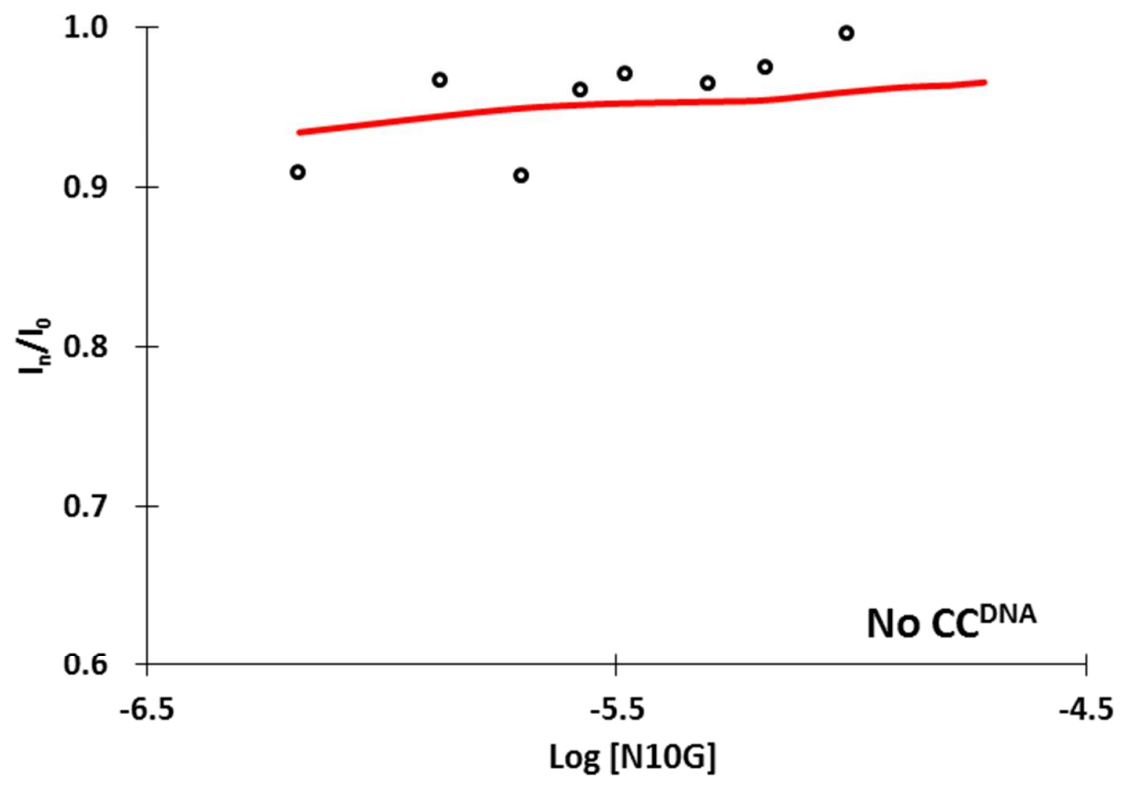

Figure S10. Fluorimetric titration of EB-DNA complexes with N10G 


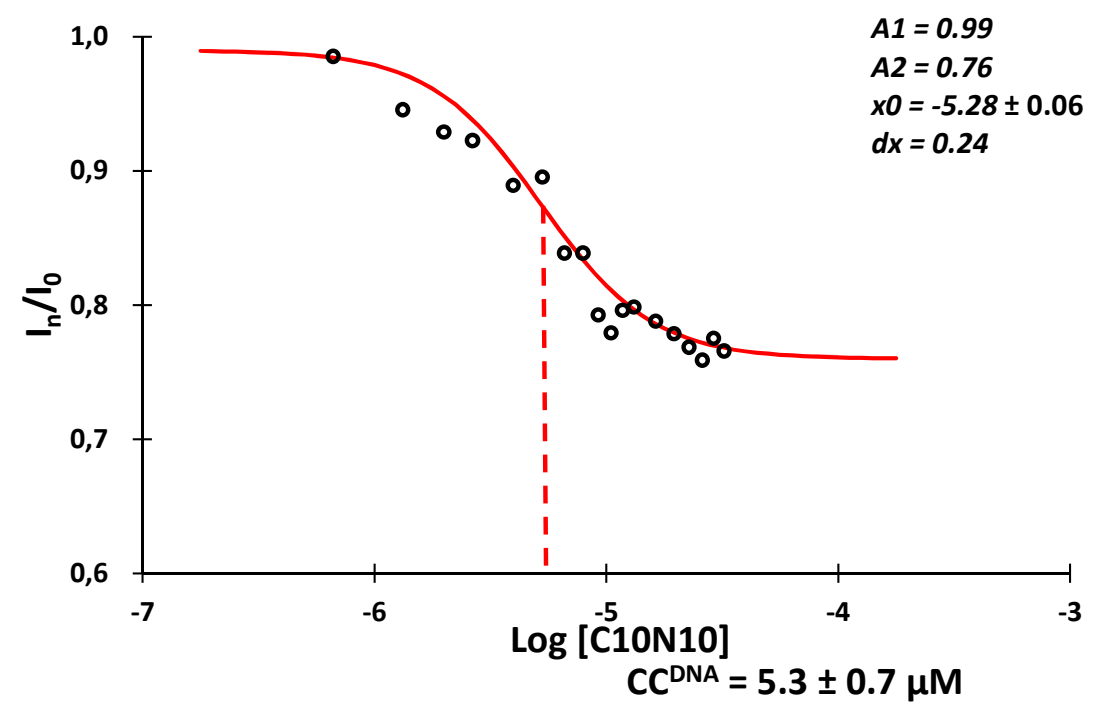

Figure S6. Fluorimetric titration of EB-DNA complexes with C10N10 